\title{
Combined Active and Reactive Power Control of Wind Farms based on Model Predictive Control
}

Zhao, Haoran; Wu, Qiuwei; Wang, Jianhui ; Liu, Zhaoxi; Shahidehpour, Mohammad ; Xue, Yusheng

Published in:

IEEE Transactions on Energy Conversion

Link to article, DOI:

10.1109/TEC.2017.2654271

Publication date:

2017

Document Version

Peer reviewed version

Link back to DTU Orbit

Citation (APA):

Zhao, H., Wu, Q., Wang, J., Liu, Z., Shahidehpour, M., \& Xue, Y. (2017). Combined Active and Reactive Power Control of Wind Farms based on Model Predictive Control. IEEE Transactions on Energy Conversion, 32(3), 1177-1187. https://doi.org/10.1109/TEC.2017.2654271

\section{General rights}

Copyright and moral rights for the publications made accessible in the public portal are retained by the authors and/or other copyright owners and it is a condition of accessing publications that users recognise and abide by the legal requirements associated with these rights.

- Users may download and print one copy of any publication from the public portal for the purpose of private study or research.

- You may not further distribute the material or use it for any profit-making activity or commercial gain

- You may freely distribute the URL identifying the publication in the public portal 


\title{
Combined Active and Reactive Power Control of Wind Farms based on Model Predictive Control
}

\author{
Haoran Zhao, Qiuwei Wu, Jianhui Wang, Zhaoxi Liu, Mohammad Shahidehpour and Yusheng Xue
}

\begin{abstract}
This paper proposes a combined wind farm controller based on Model Predictive Control (MPC). Compared with the conventional decoupled active and reactive power control, the proposed control scheme considers the significant impact of active power on voltage variations due to the low $X / R$ ratio of wind farm collector systems. The voltage control is improved. Besides, by coordination of active and reactive power, the Var capacity is optimized to prevent potential failures due to Var shortage, especially when the wind farm operates close to its full load. An analytical method is used to calculate the sensitivity coefficients to improve the computation efficiency and overcome the convergence problem. Two control modes are designed for both normal and emergency conditions. A wind farm with 20 wind turbines was used to verify the proposed combined control scheme.
\end{abstract}

Index Terms-Active power control, combined control, model predictive control, reactive power control, wind farm.

\section{INTRODUCTION}

W IND power is the world's fastest growing energy source and is one of the most rapidly expanding industries [1]. The increasing penetration of wind power and growing size of wind farms have introduced new challenges to the system operation [2]. Modern wind farms are required to meet more stringent technical requirements specified by system operators, which include active power regulation capability and voltage operating range at the Point of Connection (POC) [3].

In the conventional wind farm control, there is no coupling between the active and reactive power controller, and the active and reactive power is controlled separately [4]-[6]. For active power control, by coordination of individual Wind Turbine Generators (WTGs), a wind farm shall track the power reference from a system operator [5]. In recent studies, the reduction of fatigue loads experienced by WTGs is taken as another control objective to extend their lifetime [6]-[9]. For reactive power control, besides WTGs, other fast Var

H. Zhao and Z. Liu are with Center for Electric Power and Energy (CEE), Department of Electrical Engineering, Technical University of Denmark (DTU), Kgs. Lyngby, 2800 Denmark (e-mail: hzhao@elektro.dtu.dk; zhliu@elektro.dtu.dk).

Q. Wu is with Center for Electric and Energy (CEE), Department of Electrical Engineering, Technical University of Denmark (DTU), Kgs. Lyngby, 2800 Denmark and School of Electrical Engineering, Shandong University, China (e-mail: qw@elektro.dtu.dk).

J. Wang is with Center for Energy, Environmental, and Economic System Analysis (CEEESA), Argonne National Laboratory, Argonne, IL 60439, USA (e-mail: jianhui.wang@anl.gov).

M. Shahidehpour is with Electrical and Computer Engineering Department, Illinois Institute of Technology (IIT), Chicago, IL 60616, USA (e-mail: ms@iit.edu).

Y. Xue is with State Grid Electric Power Research Institute, Nanjing 210003, China (e-mail: xueyusheng@ @sgepri.sgcc.com.cn). regulation devices, such as Static Var Compensators (SVCs) and Static Var Generators (SVGs), are coordinated to regulate the voltage at the POC [10]-[12].

In wind farms, WTGs are connected through long Medium Voltage (MV) feeders, whose $X / R$ ratio is low $(X / R \leq 1)$. Accordingly, besides the reactive power change, the active power change has a significant impact on the voltage variation. It is promising to involve the active power control to improve the voltage control of wind farms by adjusting the active power references of WTGs. Compared with the sole reactive power compensation, the voltages are better controlled and the recovery of the violated voltage is faster.

Moreover, the Var capability of modern WTGs (Type 3 and Type 4) is constrained by the operating limits of the converters. Its range is dependent on the terminal voltage and active power production [13]. When WTGs operate close to their full load, the Var capacity will significantly decrease, which implies the decrease of voltage support capability. Therefore, by optimally adjusting the active power references of WTGs, the Var capacity of the whole wind farm can be optimized to deal with potential voltage disturbances.

The main contribution of the paper is proposing a combined active and reactive power control based on Model Predictive Control (MPC) to improve the wind farm voltage control. Compared to the existing methods, the advantages of the proposed method are summarized as follows.

- Firstly, during normal operation, the impact of active power on voltages in wind farms is considered and reactive power is optimally coordinated to minimize voltage deviations of the wind farm buses.

- Secondly, for emergency condition, i.e. a bus voltage violates its constraint, the active and reactive power is jointly controlled to accelerate the voltage recovery.

- Thirdly, the MPC can realize combined active and reactive power control of devices with different time constants.

In the implementation of the proposed Wind Farm Control (WFC), a hysteresis control loop is applied to prevent chattering in the switch of the designed modes. An analytical method is used to calculate the voltage sensitivity coefficients, based on the model of the wind farm collector system.

The paper is organized as follows. Section II presents the structure of the proposed WFC. The prediction models of the controlled devices for the MPC are described in Section III. The sensitivity coefficient calculation is introduced in Section IV. Section V explains the formulation of the MPC problem for the WFC. Case studies are presented and discussed in Section VI, followed by conclusions. 


\section{Wind FARM CONTROL STRUCTURE}

Fig. 1 illustrates the typical configuration of a wind farm. The buses within the wind farm include a bus at the POC, a bus at the collection point (located at MV side of the main substation transformer) and buses of WTGs.

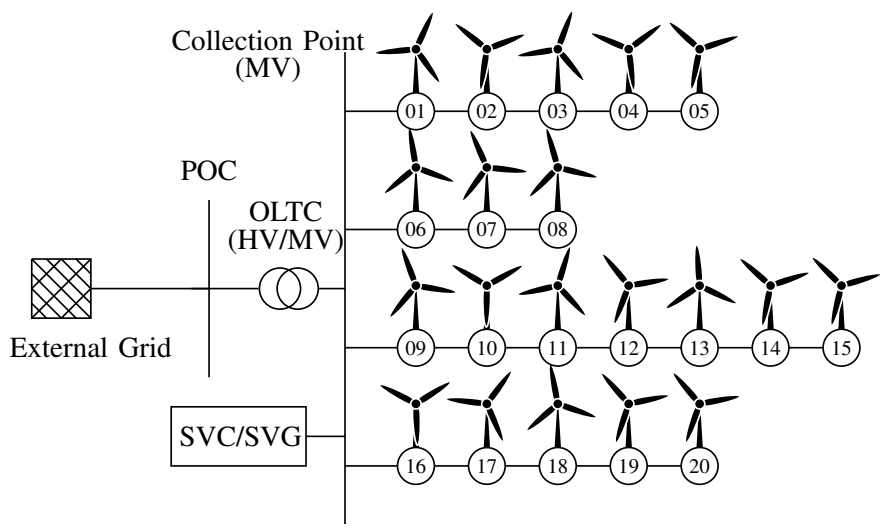

Fig. 1. Configuration of a wind farm.

The proposed WFC structure is shown in Fig. 2. The active power and voltage references at the POC of the wind farm, $P_{\mathrm{wf}}^{\text {ref }}$ and $V_{\mathrm{poc}}^{\mathrm{ref}}$, are decided by the system operator and delivered to the WFC. The measurements of individual WTGs and SVCs/SVGs are sent directly to the WFC. Based on the calculated voltage sensitivities $\left(\frac{\partial V}{\partial P}, \frac{\partial V}{\partial Q}\right)$ and the prediction models of WTGs and SVCs/SVGs, the MPC problem is formulated. By solving the MPC problem, the regulation commands for all WTGs $\left(P_{\mathrm{wt}}^{\mathrm{ref}}, Q_{\mathrm{wt}}^{\mathrm{ref}}\right)$ and SVCs/SVGs $\left(V_{\mathrm{s}}^{\mathrm{ref}}\right)$ are determined and delivered to their local controllers.

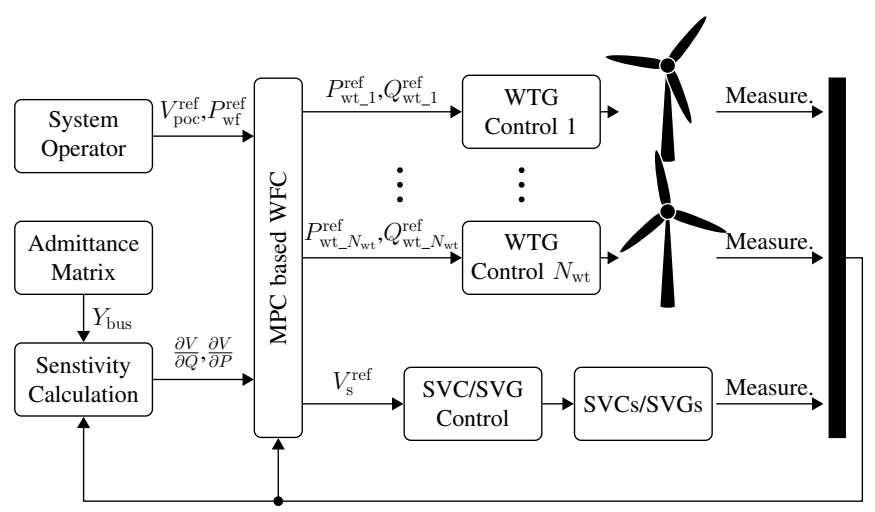

Fig. 2. Wind farm control structure.

According to different voltage conditions, the WFC has two control modes. (1) Normal mode. In this mode, the voltages of the wind farm are within the constraints. The active power control ( $P$ control) plays the major role. By optimal dispatch of $P_{\mathrm{wt}}^{\mathrm{ref}}$, power reference $P_{\mathrm{wf}}^{\mathrm{ref}}$ is tracked and the fatigue loads of WTGs are minimized. The impact of $P_{\mathrm{wt}}$ on the bus voltages can be estimated based on the voltage sensitivity. Accordingly, the reactive power control ( $Q$ control) is coordinated by regulation of $Q_{\mathrm{wt}}$ and $Q_{\mathrm{s}}$ to further minimize the deviation of bus voltages $\left(V_{\mathrm{poc}}, V_{\mathrm{wt}}\right)$ from their references and maximize the fast Var reserve to handle potential disturbances in the future. (2) Emergency mode. In this mode, there exists a voltage violation. The correction of the violated bus voltage is the primary control objective. The $P$ and $Q$ controls are coordinated to explore the maximum voltage support capability, by compromising the active power control and the voltage control of other buses. In other words, for the $P$ control, the minimization of fatigue loads is not considered. For the $Q$ control, the deviation of the violated bus voltage has a higher priority to be minimized, compared with the other bus voltages.

Due to the fast development of power electronics technology, modern WTGs are capable of tracking $P_{\mathrm{wt}}^{\mathrm{ref}}$ and $Q_{\mathrm{wt}}^{\mathrm{ref}}$. For the $P$ control, based on $P_{\mathrm{wt}}^{\mathrm{ref}}$, the generator torque reference $T_{\mathrm{g}}^{\mathrm{ref}}$ and pitch angle reference $\theta^{\text {ref }}$ are generated in the local WTG controller. For the $Q$ control, $Q_{\mathrm{wt}}^{\mathrm{ref}}$ is sent to the converter's constant- $Q$ control loop. More details are described in Section III-A.

The SVCs/SVGs can operate under either constant- $V$ mode or constant- $Q$ mode. In this study, the constant- $V$ mode is adopted. Compared with the constant- $Q$ mode, the SVCs/SVGs can provide dynamic Var support to regulate the voltage of the controlled bus (POC in this study) in time [11]. Based on the prediction model and $V_{\mathrm{s}}^{\text {ref }}$, the equivalent Var reference $Q_{\mathrm{s}}^{\text {ref }}$ can be calculated and coordinated with the WTGs. More details are described in Section III-B.

\section{Modeling OF WTG AND SVC/SVG}

The models of WTGs and SVCs/SVGs are described in this section. The combined discrete system model is derived, which is used as the prediction model for the MPC.

\section{A. Modeling of WTG}

In the WFC, a WTG is considered as an actuator, which follows the assigned power commands $P_{\mathrm{wt}}^{\mathrm{ref}}$ and $Q_{\mathrm{wt}}^{\mathrm{ref}}$. The $P$ and $Q$ control loops are decoupled.

1) P loop: The power-controlled WTG model was developed by National Renewalbe Energy Laboratory (NREL) to represent a variable speed pitch-controlled wind turbine [15], [16]. The model structure is shown in Fig. 3, which consists of aerodynamics, a drivetrain, generator, pitch actuator, tower and local WTG controller.

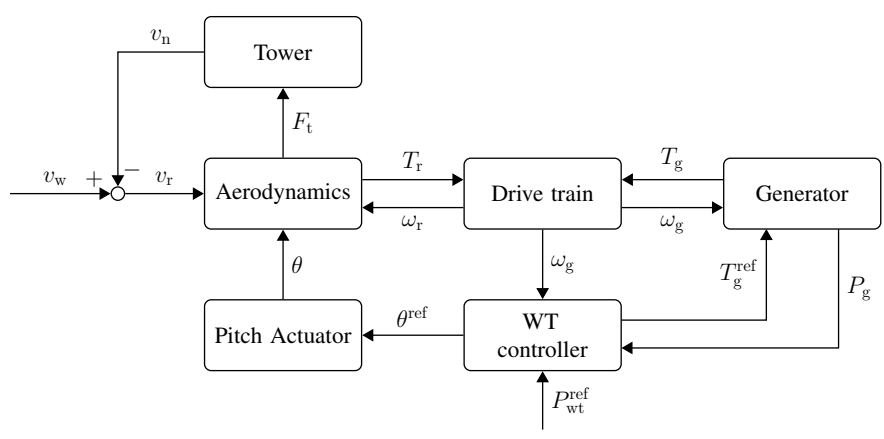

Fig. 3. Single wind turbine system [15].

Since the sampling time of the WFC is normally in seconds, the fast dynamics of the generator torque control and pitch actuator are neglected. The generator efficiency $\mu$ is compensated 
in the WTG controller. Accordingly, the active power output $P_{\mathrm{wt}}$ is approximately equal to the power reference $P_{\mathrm{wt}}^{\mathrm{ref}}$,

$$
P_{\mathrm{wt}} \approx P_{\mathrm{wt}}^{\mathrm{ref}} .
$$

The nonlinear model can be linearized around the operating points. In this study, a simplified WTG state space model, introduced in [7] is adopted, which is expressed by,

$$
\dot{x}_{\mathrm{wt}}^{p}=\boldsymbol{A}_{\mathrm{wt}}^{p} x_{\mathrm{wt}}^{p}+\boldsymbol{B}_{\mathrm{wt}}^{p} P_{\mathrm{wt}}^{\mathrm{ref}}+\boldsymbol{E}_{\mathrm{wt}}^{p},
$$

where $x_{\mathrm{wt}}^{p}$ refers to the state vector, defined by $x_{\mathrm{wt}}^{p} \triangleq$ $\left[\theta, \omega_{\mathrm{r}}, \omega_{\mathrm{f}}\right]^{\prime}, \theta$ is the pitch angle, $\omega_{\mathrm{r}}$ and $\omega_{\mathrm{f}}$ are the rotor speed and the filtered generator speed $\omega_{\mathrm{g}}$, respectively. The state space matrices are,

$$
\begin{aligned}
\boldsymbol{A}_{\mathrm{wt}}^{\boldsymbol{p}}= & {\left[\begin{array}{ccc}
0 & -\frac{K_{\mathrm{p}_{-} \theta} \eta_{\mathrm{g}}}{\tau_{\mathrm{g}}} & \frac{K_{\mathrm{p}_{-} \theta}}{\tau_{\mathrm{g}}}-K_{\mathrm{i}_{-} \theta} \\
\frac{K_{\theta T_{\mathrm{r}}}}{J_{\mathrm{t}}} & \frac{K_{\omega_{\mathrm{r}} T_{\mathrm{r}}}}{J_{\mathrm{t}}}+\frac{1}{J_{\mathrm{t}}} \frac{P_{\mathrm{wt}}^{0} \eta_{\mathrm{g}}}{\mu \omega_{\mathrm{g}}^{0^{2}}} & 0 \\
0 & \frac{\eta_{\mathrm{g}}}{\tau_{\mathrm{g}}} & -\frac{1}{\tau_{\mathrm{g}}}
\end{array}\right], } \\
\boldsymbol{B}_{\mathrm{wt}}^{\boldsymbol{p}}= & {\left[\begin{array}{c}
0 \\
-\frac{\eta_{\mathrm{g}}}{J_{\mathrm{t}} \mu \omega_{\mathrm{g}}^{0}} \\
0
\end{array}\right], \boldsymbol{E}_{\mathrm{wt}}^{p}=\left[\begin{array}{c}
0 \\
\frac{K_{v_{\mathrm{w}} T_{\mathrm{r}} v_{\mathrm{w}}^{0}}^{J_{\mathrm{t}}}}{0}
\end{array}\right], }
\end{aligned}
$$

where $\eta_{\mathrm{g}}$ is the gearbox ratio, $J_{\mathrm{t}} \triangleq J_{\mathrm{r}}+\eta_{\mathrm{g}}^{2} J_{\mathrm{g}}$ is the equivalent inertia, $\tau_{\mathrm{g}}$ is the time constant of the generator speed filter and $T_{\mathrm{r}}$ is the rotor torque. $P_{\mathrm{wt}}^{0}, \theta^{0}, \omega_{\mathrm{g}}^{0}$, and $v_{\mathrm{w}}^{0}$ denote the measured power output, pitch angle, generator speed and wind speed at the operating point, respectively. $K_{\mathrm{p}_{\_} \theta}, K_{\mathrm{i}_{-} \theta}$ denote the proportional and integral gains of the pitch controller. $K_{\theta T_{\mathrm{r}}}$, $K_{\omega_{\mathrm{r}} T_{\mathrm{r}}}, K_{v_{\mathrm{w}} T_{\mathrm{r}}}$ are the coefficients derived from the Taylor approximation of $T_{\mathrm{r}}$ at the operating point.

2) $Q$ loop: The dynamic behaviour of the constant- $Q$ control of WTGs can be described by a first order function [17]. The response time is in the range of $1 \sim 10 \mathrm{~s}$ [18]. The state space model is,

$$
\dot{x}_{\mathrm{wt}}^{q}=\boldsymbol{A}_{\mathrm{wt}}^{q} x_{\mathrm{wt}}^{q}+\boldsymbol{B}_{\mathrm{wt}}^{q} Q_{\mathrm{wt}}^{\mathrm{ref}},
$$

where $x_{\mathrm{wt}}^{q}$ is the state variable, defined by $x_{\mathrm{wt}}^{q} \triangleq Q_{\mathrm{wt}}$. The state matrices are,

$$
\boldsymbol{A}_{\mathrm{wt}}^{q}=-\frac{1}{\tau_{\mathrm{q}}}, B_{\mathrm{wt}}^{q}=\frac{1}{\tau_{\mathrm{q}}},
$$

where $\tau_{\mathrm{q}}$ is the time constant of the $Q$ loop.

\section{B. Modeling of SVC/SVG}

The dynamics of the constant- $Q$ control loop of SVC/SVG can be described by a first order function [19],

$$
Q_{\mathrm{s}}=\frac{1}{1+s \tau_{\mathrm{s}}} Q_{\mathrm{s}}^{\mathrm{ref}},
$$

where $\tau_{\mathrm{s}}$ is the time constant, which is within milliseconds (50 $200 \mathrm{~ms}$ for SVCs and $20 \sim 100 \mathrm{~ms}$ for SVGs) [20].

As the control input, $V_{\mathrm{S}}^{\text {ref }}$ is sent to the local PI controller to adjust the Var output. The equivalent Var reference $Q_{\mathrm{s}}^{\text {ref }}$ can be calculated by,

$$
Q_{\mathrm{s}}^{\mathrm{ref}}=Q_{\mathrm{s}}^{0}+K_{\mathrm{p}_{-} \mathrm{s}}\left(V_{\mathrm{s}}^{\mathrm{ref}}-V_{\mathrm{s}}\right)+K_{\mathrm{i}_{-} \mathrm{s}} \frac{1}{s}\left(V_{\mathrm{s}}^{\mathrm{ref}}-V_{\mathrm{s}}\right),
$$

where $Q_{\mathrm{s}}^{0}$ is the reactive power at the operating point, $K_{\mathrm{p}_{-} \mathrm{s}}$ and $K_{\mathrm{i}_{\mathrm{s}} \mathrm{s}}$ are the proportional and integral gains of the PI controller, respectively.

The voltage at the controlled bus (POC) $V_{\mathrm{s}}$ is dependent on the changes of $P_{\mathrm{wt}}, Q_{\mathrm{wt}}$ and $Q_{\mathrm{s}} . \Delta$ indicates the variable change, i.e. $\Delta P_{\mathrm{wt}} \triangleq P_{\mathrm{wt}}-P_{\mathrm{wt}}^{0}, \Delta Q_{\mathrm{wt}} \triangleq Q_{\mathrm{wt}}-Q_{\mathrm{wt}}^{0}, \Delta Q_{\mathrm{s}} \triangleq$ $Q_{\mathrm{s}}-Q_{\mathrm{s}}^{0} . V_{\mathrm{s}}$ can be derived by,

$$
V_{\mathrm{s}}=V_{\mathrm{s}}^{0}+\frac{\partial\left|V_{\mathrm{s}}\right|}{\partial Q_{\mathrm{s}}} \Delta Q_{\mathrm{s}}+\frac{\partial\left|V_{\mathrm{s}}\right|}{\partial P_{\mathrm{wt}}} \Delta P_{\mathrm{wt}}+\frac{\partial\left|V_{\mathrm{s}}\right|}{\partial Q_{\mathrm{wt}}} \Delta Q_{\mathrm{wt}} .
$$

By defining $V_{\text {int }}$ as the integral of the deviation between $V_{\mathrm{s}}^{\mathrm{ref}}$ and $V_{\mathrm{s}}$,

$$
V_{\text {int }} \triangleq \frac{V_{\mathrm{s}}^{\mathrm{ref}}-V_{\mathrm{s}}}{s},
$$

Equations (4)-(7) can be rewritten as the following state space form,

$$
\dot{x}_{\mathrm{s}}=\boldsymbol{A}_{\mathrm{s}} x_{\mathrm{s}}+\boldsymbol{B}_{\mathrm{s}} V_{\mathrm{s}}^{\mathrm{ref}}+\boldsymbol{E}_{\mathrm{s}} P_{\mathrm{wt}}+\boldsymbol{F}_{\mathrm{s}} Q_{\mathrm{wt}}+\boldsymbol{G}_{\mathrm{s}},
$$

where $x_{\mathrm{s}}$ is the state vector, defined by $x_{\mathrm{s}} \triangleq\left[Q_{\mathrm{s}}, V_{\mathrm{int}}\right]^{\prime}$. The state space matrices are,

$$
\begin{aligned}
& \boldsymbol{A}_{\mathbf{s}}=\left[\begin{array}{cc}
-\frac{1}{\tau_{\mathrm{s}}}\left(1+K_{\mathrm{p} \_\mathrm{s}} \frac{\partial\left|V_{\mathrm{s}}\right|}{\partial Q_{\mathrm{s}}}\right) & \frac{K_{\mathrm{i} \_\mathrm{s}}}{\tau_{\mathrm{s}}} \\
-\frac{\partial\left|V_{\mathrm{s}}\right|}{\partial Q_{\mathrm{s}}} & 0
\end{array}\right], \boldsymbol{B}_{\mathrm{s}}=\left[\begin{array}{c}
\frac{K_{\mathrm{p} \_\mathrm{s}}}{\tau_{\mathrm{s}}} \\
1
\end{array}\right], \\
& \boldsymbol{E}_{\mathbf{s}}=\left[\begin{array}{c}
-\frac{K_{\mathrm{p} \_\mathrm{s}}}{\tau_{\mathrm{s}}} \frac{\partial\left|V_{\mathrm{s}}\right|}{\partial P_{\mathrm{wt}}} \\
-\frac{\partial\left|V_{\mathrm{s}}\right|}{\partial P_{\mathrm{wt}}}
\end{array}\right], \boldsymbol{F}_{\mathrm{s}}=\left[\begin{array}{c}
-\frac{K_{\mathrm{p} \_\mathrm{s}}}{\tau_{\mathrm{s}}} \frac{\partial\left|V_{\mathrm{s}}\right|}{\partial Q_{\mathrm{wt}}} \\
-\frac{\partial\left|V_{\mathrm{s}}\right|}{\partial Q_{\mathrm{wt}}}
\end{array}\right], \\
& \boldsymbol{G}_{\mathbf{s}}=\left[\begin{array}{c}
-\frac{K_{\mathrm{p} \_\mathrm{s}} \Delta V_{\mathrm{s}}^{0}}{\tau_{\mathrm{s}}}+\frac{Q_{\mathrm{s}}^{0}}{\tau_{\mathrm{s}}} \\
-\Delta V_{\mathrm{s}}^{0}
\end{array}\right],
\end{aligned}
$$

where

$$
\Delta V_{\mathrm{s}}^{0} \triangleq V_{\mathrm{s}}^{0}-\frac{\partial\left|V_{\mathrm{s}}\right|}{\partial Q_{\mathrm{s}}} Q_{\mathrm{s}}^{0}-\frac{\partial\left|V_{\mathrm{s}}\right|}{\partial P_{\mathrm{wt}}} P_{\mathrm{wt}}^{0}-\frac{\partial\left|V_{\mathrm{s}}\right|}{\partial Q_{\mathrm{wt}}} Q_{\mathrm{wt}}^{0} .
$$

More details of the derivation of (8) are presented in Appendix.

\section{Combined system model}

The aforementioned $P, Q$ loops of WTG and SVC/SVG models can be merged. The combined system model, which consists of $N_{\mathrm{wt}}$ WTGs and $1 \mathrm{SVC} / \mathrm{SVG}$, can be formulated as the following state space form,

$$
\dot{x}=\boldsymbol{A} x+\boldsymbol{B} u+\boldsymbol{E},
$$

where $x$ and $u$ refer to the state vector and control input vector, respectively, defined by,

$$
\begin{aligned}
& x \triangleq\left[x_{\mathrm{wt} \_1}^{p}, \cdots, x_{\mathrm{wt} \_N_{\mathrm{wt}}}^{p}, x_{\mathrm{wt} \_1}^{q}, \cdots, x_{\mathrm{wt} \_N_{\mathrm{wt}}}^{q}, x_{\mathrm{s}}{ }^{\prime}\right]^{\prime}, \\
& u \triangleq\left[u_{\mathrm{wt} \_}^{p}{ }^{\prime}, \cdots, u_{\mathrm{wt} \_N_{\mathrm{wt}}}^{p}, u_{\mathrm{wt} \_1}^{q}, \cdots, u_{\mathrm{wt} \_N_{\mathrm{wt}}}^{q}, u_{\mathrm{s}}{ }^{\prime}\right]^{\prime} .
\end{aligned}
$$

The state matrices are,

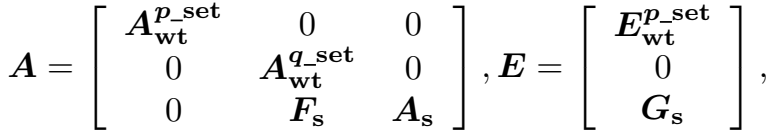

$$
\begin{aligned}
& \boldsymbol{B}=\left[\begin{array}{ccc}
\boldsymbol{B}_{\mathrm{wt}}^{p_{\mathrm{s}} \mathrm{set}} & 0 & 0 \\
0 & \boldsymbol{B}_{\mathrm{wt}}^{q_{\mathrm{s}}} & 0 \\
\boldsymbol{E}_{\mathrm{s}} & 0 & \boldsymbol{B}_{\mathrm{s}}
\end{array}\right] \text {. }
\end{aligned}
$$


where $\boldsymbol{A}_{\mathrm{wt}}^{p_{-} \text {set }}, \boldsymbol{B}_{\mathrm{wt}}^{p_{-} \text {set }}$ and $\boldsymbol{E}_{\mathrm{wt}}^{p_{\mathrm{w}} \text { set }}$ are the diagonal matrices whose diagonal entries are the corresponding state space matrices of WTG model in (2). $\boldsymbol{A}_{\mathbf{s}}, \boldsymbol{B}_{\mathbf{s}}, \boldsymbol{E}_{\mathbf{s}}, \boldsymbol{F}_{\mathbf{s}}$ and $\boldsymbol{G}_{\mathbf{s}}$ are the state space matrices of SVC/SVG model in (8).

Based on the sampling time $t_{\mathrm{s}}$, the derived continuous model (9) can be transformed into the discrete form,

$$
x(k+1)=\boldsymbol{A}_{\mathbf{d}} x(k)+\boldsymbol{B}_{\mathbf{d}} u(k)+\boldsymbol{E}_{\mathbf{d}},
$$

where $k$ is the step index. The state space matrices $\left(\boldsymbol{A}_{\mathrm{d}}, \boldsymbol{B}_{\mathrm{d}}\right.$, $\boldsymbol{E}_{\mathbf{d}}$ ) can be calculated with the method in [21].

\section{Local constraints}

1) WTG: For WTGs, according to [16], the constraints include,

$$
\begin{gathered}
\theta(k) \in\left[\theta_{\min }, \theta_{\max }\right], \Delta \theta(k) \in\left[-\Delta \theta_{\lim }, \Delta \theta_{\lim }\right], \\
\omega_{\mathrm{r}}(k) \in\left[\omega_{\min }, \omega_{\max }\right], \\
P_{\mathrm{wt}}^{\mathrm{ref}}(k) \in\left[0, P_{\mathrm{wt}}^{\text {avi }}(k)\right],
\end{gathered}
$$

where $\theta_{\min }$ and $\theta_{\max }$ are the minimum and maximum values of $\theta, \Delta \theta_{\text {lim }}$ is the ramp rate limit, $\omega_{\min }$ and $\omega_{\max }$ are the minimum and maximum values of $\omega_{\mathrm{r}}$, and $P_{\mathrm{wt}}^{\text {avi }}$ is the available wind power.

Besides, for modern WTGs (Type 3 and Type 4), the Var capacity is constrained by the operating limits of the converters [13]. The range of Var capacity of full-converter WTGs is larger due to the increased rating of the converter. A typical $P Q$ capacity curve of a full-converter WTG is illustrated in Fig. 4. The Var constraint is,

$$
Q_{\mathrm{wt}}^{\mathrm{ref}}(k) \in\left[Q_{\mathrm{wt}}^{\min }(k), Q_{\mathrm{wt}}^{\max }(k)\right],
$$

where $Q_{\mathrm{wt}}^{\min }$ and $Q_{\mathrm{wt}}^{\max }$ are the minimum and maximum values of the Var capacity, which are dependent on the terminal voltage and active power [13],

$$
Q_{\mathrm{wt}}^{\min }=f_{Q}^{\min }\left(P_{\mathrm{wt}}, V_{\mathrm{wt}}\right), Q_{\mathrm{wt}}^{\max }=f_{Q}^{\max }\left(P_{\mathrm{wt}}, V_{\mathrm{wt}}\right) .
$$

The functions $f_{\mathrm{Q}}^{\min }$ and $f_{\mathrm{Q}}^{\max }$ are nonlinear, which can be either expressed as the piece-wise affine functions or look-up tables. For the former case, $Q_{\mathrm{wt}}^{\min }$ and $Q_{\mathrm{wt}}^{\max }$ can be calculated based on the explicit form of the functions. For the latter case, $Q_{\mathrm{wt}}^{\min }$ and $Q_{\mathrm{wt}}^{\max }$ can be derived according to the interpolation. In this study, the former case is used.

By defining $Q_{\mathrm{wt}}^{\min 0}$ and $Q_{\mathrm{wt}}^{\max 0}$ as the minimum and maximum Var capacities at the operating point. $Q_{\mathrm{wt}}^{\min }$ and $Q_{\mathrm{wt}}^{\max }$ at the $k$ th step can be predicted based on the Taylor approximation,

$$
\begin{aligned}
Q_{\mathrm{wt}}^{\min }(k) & \approx Q_{\mathrm{wt}}^{\min 0}+\frac{\partial f_{Q}^{\min }}{\partial P_{\mathrm{wt}}} \Delta P_{\mathrm{wt}}(k)+\frac{\partial f_{Q}^{\min }}{\partial V_{\mathrm{wt}}} \Delta V_{\mathrm{wt}}(k), \\
Q_{\mathrm{wt}}^{\max }(k) & \approx Q_{\mathrm{wt}}^{\max 0}+\frac{\partial f_{Q}^{\max }}{\partial P_{\mathrm{wt}}} \Delta P_{\mathrm{wt}}(k)+\frac{\partial f_{Q}^{\max }}{\partial V_{\mathrm{wt}}} \Delta V_{\mathrm{wt}}(k) .
\end{aligned}
$$

The calculation of the Var capacity sensitivities in (16)-(17) are described in Section IV-B.

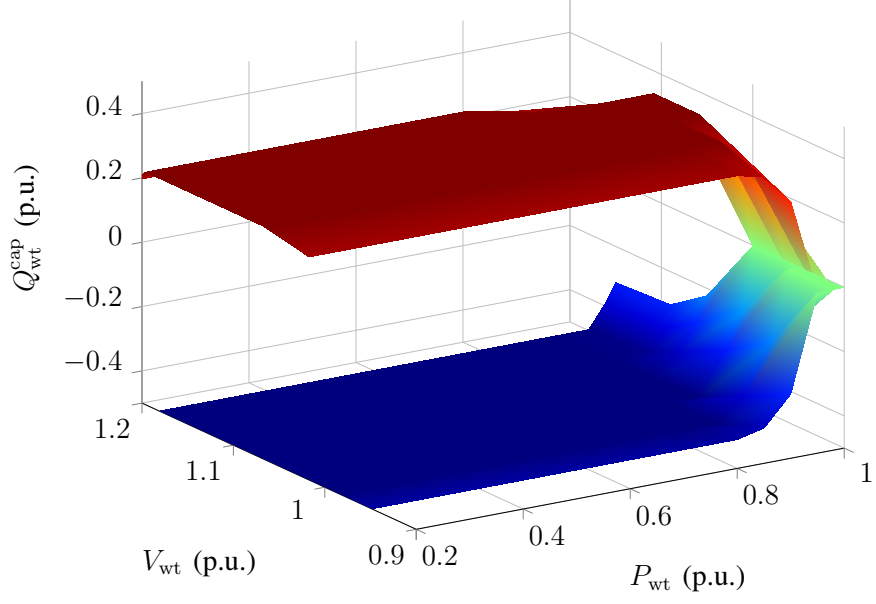

Fig. 4. $P Q$ capacity curve of a full-converter WTG.

2) SVC/SVG: For SVCs/SVGs, the constraints include,

$$
\begin{gathered}
Q_{\mathrm{s}}^{\min } \leq \Delta Q_{\mathrm{s}}+Q_{\mathrm{s}}^{0} \leq Q_{\mathrm{s}}^{\max }, \\
V_{\mathrm{s}}^{\mathrm{min}} \leq V_{\mathrm{s}}^{\mathrm{ref}} \leq V_{\mathrm{s}}^{\max },
\end{gathered}
$$

where $Q_{\mathrm{s}}^{\min }$ and $Q_{\mathrm{s}}^{\max }$ are the minimum and maximum $\operatorname{Var}$ capacities of SVCs/SVGs, respectively, $V_{\mathrm{s}}^{\min }$ and $V_{\mathrm{s}}^{\max }$ are the minimum and maximum feasible voltages.

\section{Sensitivity Calculation}

In this section, the calculations of voltage sensitivities and Var capacity sensitivities are described.

\section{A. Voltage Sensitivity}

Conventionally, the voltage sensitivity coefficients are calculated through an updated Jacobian matrix derived from the Newton-Raphson (NR) method for the load-flow solution. However, sometimes, the low $X / R$ ratio of the wind farm network makes the NR method fail to converge in solving the load-flow problem [22]. Moreover, the Jacobian matrix is dependent on the operation conditions and needs to be rebuilt and inversed for every change, which makes it impractical for real-time controllers [23].

An analytical computation method for calculating the sensitivity coefficients was developed in [23] to improve the computation efficiency. It was initially applied in the radial distribution system. Since the collector system of wind farms has a similar network topology, this method is adopted in this study.

Consider a wind farm with $N_{\mathrm{b}}$ buses, $\mathcal{N}$ is defined as the bus set, $\mathcal{N} \triangleq\left\{1,2, \cdots N_{\mathrm{b}}\right\}$. The apparent power injection $S$ can be calculated by,

$$
\overline{S_{i}}=\overline{V_{i}} \sum_{j \in \mathcal{N}}\left(Y_{\mathrm{bus}}(i, j) V_{j}\right),
$$

where $i$ and $j$ are the bus indices, $Y_{\text {bus }}$ is the admittance matrix, $\bar{S}$ and $\bar{V}$ are the conjugates of $S$ and $V$, respectively. The partial derivatives of $\overline{S_{i}}$ at Bus $i \in \mathcal{N}$ with respect to 
active power $P_{l}$ and reactive power $Q_{l}$ at Bus $l \in \mathcal{N}$ can be derived as (21) and (22), respectively,

$$
\begin{aligned}
& \frac{\partial \overline{S_{i}}}{\partial P_{l}}=\frac{\partial\left\{P_{i}-\mathrm{j} Q_{i}\right\}}{\partial P_{l}}=\frac{\partial \overline{V_{i}}}{\partial P_{l}} \sum_{j \in \mathcal{N}} Y_{\mathrm{bus}}(i, j) V_{j}+ \\
& \overline{V_{i}} \sum_{j \in \mathcal{N}} Y_{\text {bus }}(i, j) \frac{\partial V_{j}}{\partial P_{l}}=\left\{\begin{array}{l}
1, \text { if } i=l . \\
0, \text { else. }
\end{array}\right. \\
& \frac{\partial \overline{S_{i}}}{\partial Q_{l}}=\frac{\partial\left\{P_{i}-\mathrm{j} Q_{i}\right\}}{\partial Q_{l}}=\frac{\partial \overline{V_{i}}}{\partial Q_{l}} \sum_{j \in \mathcal{N}} Y_{\mathrm{bus}}(i, j) V_{j}+ \\
& \overline{V_{i}} \sum_{j \in \mathcal{N}} Y_{\text {bus }}(i, j) \frac{\partial V_{j}}{\partial Q_{l}}=\left\{\begin{array}{cl}
-\mathrm{j} 1, & \text { if } i=l . \\
0, & \text { else. }
\end{array}\right.
\end{aligned}
$$

The system of (21) is linear to the unknown variables $\frac{\partial V_{i}}{\partial P_{l}}$, $\frac{\partial \overline{V_{i}}}{\partial P_{l}}$ and (22) is linear to the unknown variables $\frac{\partial V_{i}}{\partial Q_{l}}, \frac{\partial \overline{V_{i}}}{\partial Q_{l}}$. According to the theorem in [23], (21) and (22) have a unique solution for radial electrical networks.

Once $\frac{\partial V_{i}}{\partial Q_{l}}, \frac{\partial \overline{V_{i}}}{\partial Q_{l}}$ are obtained, the partial derivatives of the voltage magnitude $\frac{\partial\left|V_{i}\right|}{Q_{l}}$ can be calculated by,

$$
\frac{\partial\left|V_{i}\right|}{\partial P_{l}}=\frac{1}{\left|V_{i}\right|} \operatorname{Re}\left(\overline{V_{i}} \frac{\partial V_{i}}{\partial P_{l}}\right), \quad \frac{\partial\left|V_{i}\right|}{\partial Q_{l}}=\frac{1}{\left|V_{i}\right|} \operatorname{Re}\left(\overline{V_{i}} \frac{\partial V_{i}}{\partial Q_{l}}\right) .
$$

\section{B. Var capacity sensitivity}

If the analytical expressions of $f_{\mathrm{Q}}^{\min }$ and $f_{\mathrm{Q}}^{\max }$ are known, the analytical equation of the sensitivities $\left(\frac{\partial f_{\mathrm{Q}}^{\min }}{\partial P_{\mathrm{wt}}}, \frac{\partial f_{\mathrm{Q}}^{\min }}{\partial V_{\mathrm{wt}}}, \frac{\partial f_{\mathrm{Q}}^{\max }}{\partial P_{\mathrm{wt}}}\right.$ and $\left.\frac{\partial f_{\mathrm{Q}}^{\max }}{\partial V_{\mathrm{wt}}}\right)$ can be derived. If the lookup table of the $P Q$ curve is available, the sensitivities can be approximately derived according to the interpolation, such as,

$$
\frac{\partial f_{Q}^{\min }}{\partial P_{\mathrm{wt}}}=\frac{f_{\min }\left(P_{\mathrm{wt}}^{0}+\Delta P_{\mathrm{wt}}, V_{\mathrm{wt}}^{0}\right)-f_{\min }\left(P_{\mathrm{wt}}^{0}, V_{\mathrm{wt}}^{0}\right)}{\Delta P_{\mathrm{wt}}} \text {. }
$$

The other sensitivity coefficients can be calculated in a similar way.

\section{MPC PROBLEM Formulation}

In this section, the cost functions and the constraints of the MPC are formulated for the two designed control modes.

The sampling period of the WFC is $t_{\mathrm{s}}$ and the prediction period is $t_{\mathrm{p}}$. Compared with the time constants of the fast Var devices, $t_{\mathrm{s}}$ is larger, which is normally in seconds. In order to capture the fast dynamics, the sampling period of the prediction should be smaller. Thus, $t_{\mathrm{s}}$ is further divided into $n_{\mathrm{s}}$ steps. Accordingly, the total number of prediction steps can be calculated by $n_{\mathrm{p}}=\frac{t_{\mathrm{p}}}{t_{\mathrm{s}}} n_{\mathrm{s}}$.

\section{A. Normal mode}

If all the measured bus voltages of the wind farm are within their thresholds, i.e. $\left\|V_{\text {poc }}^{0}-V_{\text {poc }}^{\text {ref }}\right\| \leq V_{\text {poc }}^{\text {th }}$ and $\left\|V_{\mathrm{wt}}^{0}-V_{\mathrm{wt}}^{\mathrm{ref}}\right\| \leq V_{\mathrm{wt}}^{\mathrm{th}}$, the WFC will operate in this mode. $V_{\mathrm{poc}}^{0}$ is the measured voltages at the POC. $V_{\mathrm{wt}}^{0}$ is the vector of the WTG bus voltages, defined as $V_{\mathrm{wt}}^{0} \triangleq\left[V_{\mathrm{wt} \_1}^{0}, V_{\mathrm{wt} \_2}^{0}, \cdots\right]^{\prime}$. $V_{\text {poc }}^{\text {ref }}$ is the reference value from the system operator (typically 1.0 p.u.) and $V_{\mathrm{wt}}^{\mathrm{ref}}$ is the nominal voltage of each WTG (typically 1.0 p.u.). $V_{\mathrm{poc}}^{\mathrm{th}}$ and $V_{\mathrm{wt}}^{\mathrm{th}}$ refer to the thresholds of $V_{\text {poc }}$ and $V_{\text {wt }}$, respectively. $V_{\text {poc }}^{\text {th }}$ differs according to different requirements of grid codes.
1) Cost function: The control objective of this mode is threefold. Firstly, the fatigue loads of WTGs are minimized. In this study, only the fatigue load of the drivetrain is considered. The shaft torque $T_{\mathrm{s}}$ is transferred through the gearbox. Since the gearbox is a vulnerable component, the oscillation of $T_{\mathrm{s}}$ may create micro-cracks in the material and lead to the component failure. The load alleviation can be realized by reducing the deviation of $T_{\mathrm{s}}$, i.e.

$$
\operatorname{Obj} 1=\sum_{k=1}^{n_{\mathrm{p}}}\left\|\Delta T_{\mathrm{s}}(k)\right\|_{W_{T_{\mathrm{s}}}}^{2}
$$

where $\Delta T_{\mathrm{s}}(k) \triangleq T_{\mathrm{S}}(k)-T_{\mathrm{s}}^{0}$ and $W_{T_{\mathrm{s}}}$ is the weighting factor. Based on (2), $T_{\mathrm{S}}$ can be derived by,

$$
\begin{gathered}
T_{\mathrm{s}}=\boldsymbol{C}_{\mathbf{w t}}^{\boldsymbol{p}} x_{\mathrm{wt}}+\boldsymbol{D}_{\mathbf{w t}}^{\boldsymbol{p}} P_{\mathrm{wt}}^{\mathrm{ref}}+\boldsymbol{F}_{\mathbf{w t}}^{\boldsymbol{p}}, \\
\boldsymbol{C}_{\mathbf{w t}}^{\boldsymbol{p}}=\left[\begin{array}{lll}
\frac{\eta_{\mathrm{g}} J_{\mathrm{g}} K_{\theta T_{\mathrm{r}}}}{J_{\mathrm{t}}} & \frac{\eta_{\mathrm{g}}^{2} J_{\mathrm{g}} K_{\omega_{\mathrm{r}} T_{\mathrm{r}}}}{J_{\mathrm{t}}}-\frac{\eta_{\mathrm{g}}^{2} J_{\mathrm{r}} P_{\mathrm{wt}}^{0}}{J_{\mathrm{t}} \mu\left(\omega_{\mathrm{g}}^{0}\right)^{2}} & 0
\end{array}\right], \\
\boldsymbol{D}_{\mathbf{w t}}^{\boldsymbol{p}}=\frac{1}{\mu \omega_{\mathrm{g}}^{0}}, \boldsymbol{F}_{\mathbf{w t}}^{\boldsymbol{p}}=\frac{\eta_{\mathrm{g}}^{2} J_{\mathrm{g}} K_{v_{\mathrm{w}} T_{\mathrm{r}}} v_{\mathrm{w}}^{0}}{J_{\mathrm{t}}} .
\end{gathered}
$$

Secondly, the deviation between the measured voltages of the wind farm and their references $\left(\Delta V_{\mathrm{poc}}, \Delta V_{\mathrm{wt}}\right)$ shall be minimized, i.e.

$$
\operatorname{Obj} 2=\sum_{k=1}^{n_{\mathrm{p}}}\left(\left\|\Delta V_{\text {poc }}(k)\right\|_{W_{\text {poc }}}^{2}+\left\|\Delta V_{\mathrm{wt}}(k)\right\|_{W_{\mathrm{wt}}}^{2}\right),
$$

where $W_{\text {poc }}$ and $W_{\text {wt }}$ are their weighting factors. Since $V_{\text {poc }}$ is more concerned in this study, $W_{\text {poc }}>W_{\text {wt }} . \Delta V_{\text {poc }}(k)$ and $\Delta V_{\mathrm{wt}}(k)$ are affected by the active and reactive power injection of SVCs/SVGs and WTGs, which can be calculated by,

$$
\begin{aligned}
\Delta V_{\mathrm{poc}}(k)=V_{\mathrm{poc}}^{0} & +\frac{\partial\left|V_{\mathrm{poc}}\right|}{\partial P_{\mathrm{wt}}} \Delta P_{\mathrm{wt}}(k)+\frac{\partial\left|V_{\mathrm{poc}}\right|}{\partial Q_{\mathrm{wt}}} \Delta Q_{\mathrm{wt}}(k) \\
& +\frac{\partial\left|V_{\mathrm{poc}}\right|}{\partial Q_{\mathrm{s}}} \Delta Q_{\mathrm{s}}(k)-V_{\mathrm{poc}}^{\mathrm{ref}} \\
\Delta V_{\mathrm{wt}}^{\mathrm{pre}}(k)=V_{\mathrm{wt}}^{0} & +\frac{\partial\left|V_{\mathrm{wt}}\right|}{\partial P_{\mathrm{wt}}} \Delta P_{\mathrm{wt}}(k)+\frac{\partial\left|V_{\mathrm{wt}}\right|}{\partial Q_{\mathrm{wt}}} \Delta Q_{\mathrm{wt}}(k) \\
& +\frac{\partial\left|V_{\mathrm{wt}}\right|}{\partial Q_{\mathrm{s}}} \Delta Q_{\mathrm{s}}(k)-V_{\mathrm{wt}}^{\mathrm{ref}}
\end{aligned}
$$

Thirdly, the fast dynamic Var support capabilities shall be maximized to deal with potential disturbances. It is implemented by minimizing the $Q_{\mathrm{s}}$ to its middle level of the operating range $Q_{\mathrm{s}}^{\operatorname{mid}}=0.5\left(Q_{\mathrm{s}}^{\max }+Q_{\mathrm{s}}^{\min }\right)$. The Var shortage will be compensated by the slower Var devices (WTGs) for maintaining the voltage of buses throughout the wind farm, i.e.

$$
\mathrm{Obj} 3=\sum_{k=1}^{n_{\mathrm{p}}}\left\|Q_{\mathrm{s}}^{\mathrm{pre}}(k)-Q_{\mathrm{s}}^{\mathrm{mid}}\right\|_{W_{\mathrm{s}}}^{2},
$$

where $W_{\mathrm{s}}$ refers to its weighting factor.

According to (25), (27) and (30), the cost function is expressed by,

$$
\min _{u}(\mathrm{Obj} 1+\mathrm{Obj} 2+\mathrm{Obj} 3)
$$


To be noticed, since all the measured voltages of the wind farm are within the thresholds, it is not necessary to compromise the active power control performance to support voltage. Therefore, in order to guarantee the active power control performance, the term Obj1 for the fatigue load minimization has a higher priority, $W_{T_{\mathrm{s}}}$ should be set large enough. The reactive power is mainly used to minimize the voltage deviation ( $\left.\Delta V_{\mathrm{poc}}, \Delta V_{\mathrm{wt}}\right)$.

The weighting factors can be decided by the sensitivity analysis. In this study, the priority ranking is Obj1 $>$ Obj2 $>$ Obj3. Accordingly, the weighting factors can be selected by,

$\left(\frac{\partial T_{\mathrm{s}}}{\partial u}\right)^{2} W_{T_{\mathrm{s}}}>\left(\frac{\partial V_{\mathrm{poc}}}{\partial u}\right)^{2} W_{\mathrm{poc}}>\left(\frac{\partial V_{\mathrm{wt}}}{\partial u}\right)^{2} W_{\mathrm{wt}}>\left(\frac{\partial Q_{\mathrm{s}}}{\partial u}\right)^{2} W_{\mathrm{s}}$.

2) Constraints: Besides the local operation constraints of WTGs and SVCs/SVGs in (11)-(19), $P_{\mathrm{wf}}^{\mathrm{ref}}$ specified by the system operator shall be tracked which can be implemented as an equality constraint,

$$
\sum_{i=1}^{n_{\mathrm{wt}}} P_{\mathrm{wt} \_i}^{\mathrm{ref}}=P_{\mathrm{wf}}^{\mathrm{ref}}
$$

Moreover, the control inputs $u$ can only be updated at the sampling point. Therefore, the values within the sampling period are kept constant,

$$
\begin{gathered}
u\left(i \cdot n_{\mathrm{s}}+k\right)=u\left(i \cdot n_{\mathrm{s}}\right), \\
i \in\left[0, n_{\mathrm{p}}-1\right], k \in\left[0, n_{\mathrm{s}}-1\right] .
\end{gathered}
$$

\section{B. Emergency mode}

If any measured bus voltage violates its threshold, i.e. $V_{\mathrm{poc}}^{0}-V_{\mathrm{poc}}^{\mathrm{ref}} \|>V_{\mathrm{poc}}^{\mathrm{th}}$ or $\left\|V_{\mathrm{wt}}^{0}-V_{\mathrm{wt}}^{\mathrm{ref}}\right\|>V_{\mathrm{wt}}^{\mathrm{th}}$, the WFC will operate in this mode.

1) Control objective: The control objective of this mode is correcting the violated bus voltage within the limits to avoid potential cascading failures. The cost function is expressed by,

$$
\min _{u} \sum_{k=1}^{n_{\mathrm{p}}}\left(\left\|\Delta V_{\mathrm{poc}}(k)\right\|_{W_{\mathrm{poc}}}^{2}+\left\|\Delta V_{\mathrm{wt}}(k)\right\|_{W_{\mathrm{wt}}}^{2}\right) .
$$

Compared with the cost function of the normal mode, it is necessary to compromise the active power control performance to support the voltage. Therefore, the fatigue load minimization term (Obj1) and the fast Var reserve maximization term (Obj3) are removed from the cost function to relax the constraints of the active and reactive power. In that case, the active and reactive power can be fully explored to contribute to voltage support.

Different from (27), the weighting factors in (34) have two value settings according to the voltage condition. The larger value is set to the weighting factor if the corresponding voltage violates its limit, which accelerates the recovery of the voltage.

2) Constraints: The constraints of the emergency mode are identical to these of the normal mode.

The formulated MPC problem can be transformed to a standard Quadratic Programming (QP) problem. By commercial QP solvers, it can be efficiently solved in milliseconds which is suitable for online optimizations [24].

\section{Hysteresis loop}

When the WFC switches between these two modes, chattering may occur. In order to efficiently suppress the chattering, a hysteresis loop is used in this study. The hysteresis loop is realized by setting different voltage thresholds according to the mode switching conditions. Considering the protection configuration of WTGs (typically $0.9 \sim 1.1$ p.u.) and operation margins, the threshold value settings are listed in Table I.

TABLE I

THRESHOLD VALUES

\begin{tabular}{c|c|c}
\hline \hline & Nomral $\Rightarrow$ Emergency & Emergency $\Rightarrow$ Normal \\
\hline \hline$V_{\text {poc }}^{\text {th }}$ & 0.02 p.u. & 0.01 p.u. \\
\hline$V_{\text {wt }}^{\text {th }}$ & 0.08 p.u. & 0.07 p.u. \\
\hline
\end{tabular}

The control block diagram for the implementation is shown in Fig. 5. The voltage deviations within the wind farm, $\left\|V_{\mathrm{poc}}^{0}-V_{\mathrm{poc}}^{\mathrm{ref}}\right\|$ and $\left\|V_{\mathrm{wt}}^{0}-V_{\mathrm{wt}}^{\mathrm{ref}}\right\|$, are fed into the hysteresis loops. Based on the hysteresis rules and the thresholds in Table I, the switch signals $S_{\bmod 1}$ and $S_{\bmod 2}$ can be derived. According to the mode definition, the mode switch signal $S_{\text {mod }}$ can be decided: ( $\Rightarrow$ Normal, $0 \Rightarrow$ Emergency).

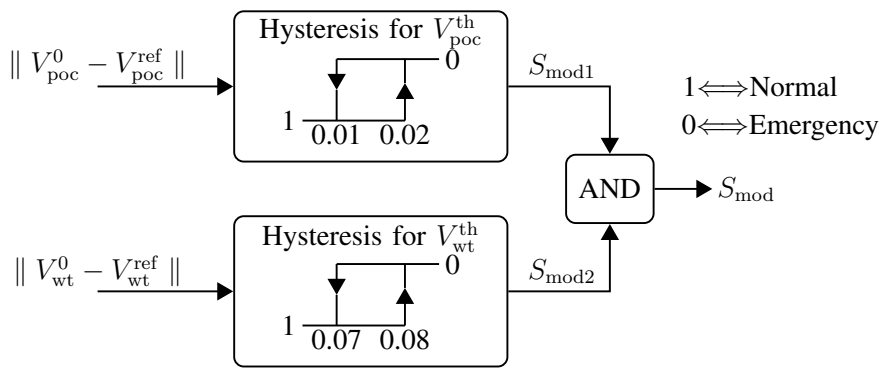

Fig. 5. Block diagram of the hysteresis loop.

\section{CASE Study}

A wind farm, comprised of $20 \times 5 \mathrm{MW}$ full-converter WTGs and $1 \times \pm 5$ MVar SVG, is used for the case study. Its configuration is shown in Fig. 1. The wind farm is integrated into the IEEE 14 bus system and the connected bus is Bus 03, which is located at the terminal of the grid, as shown in Fig. 6 . The wind field modeling considering turbulences and wake effects for the wind farm was generated from SimWindFarm [15], a toolbox for dynamic wind farm model, simulation and control.

In order to smooth out the wind power variation, the wind farm is required to limit the power production ramp rate by many system operators [25]. In this paper, the ramp rate control is applied in the WFC. The maximum ramp rate is set $10 \%$ of the installed capacity per minute $(10 \mathrm{MW} / \mathrm{min})$.

Two case scenarios are defined to test the efficacy of the proposed WFC, which represent the low and high power production operations, respectively. In both scenarios, the results of the optimal controller, where the active and reactive power are decoupled and controlled separately ('SEP'), are 


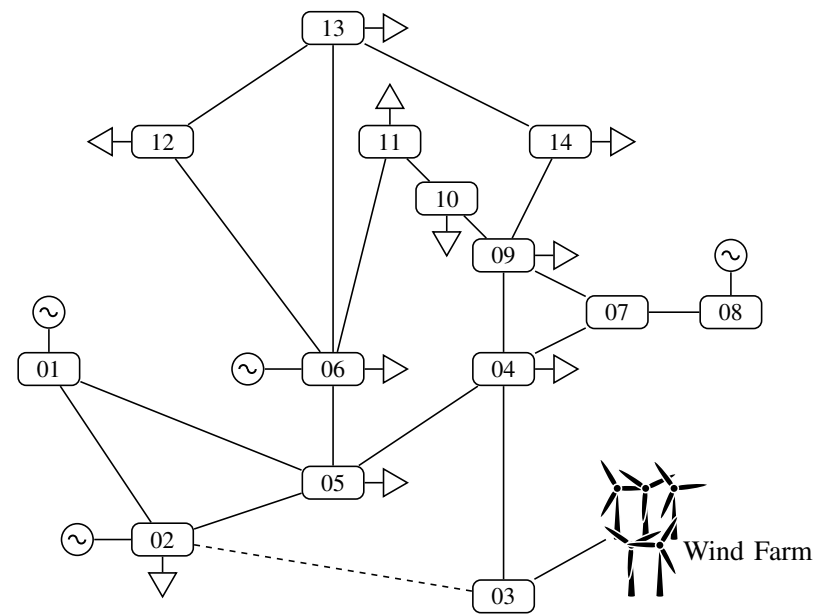

Fig. 6. IEEE 14 bus system with wind farm.

compared with those of the proposed combined MPC based WFC ('COM'). For the SEP, the active power references, $P_{\mathrm{wt}}^{\mathrm{ref}}$, are derived by solving the optimal problem,

$$
\min _{P_{\mathrm{wt}}^{\text {ref }}}(\operatorname{Obj} 1) \text {. }
$$

The reactive power references, including $Q_{\mathrm{wt}}^{\mathrm{ref}}$ and $V_{\mathrm{s}}^{\text {ref }}$, are derived by solving the optimal problem,

$$
\min _{Q_{\mathrm{wt}}^{\text {ref }}, V_{\mathrm{s}}^{\text {ref }}}(\operatorname{Obj} 2+\operatorname{Obj} 3) \text {. }
$$

Here, the definitions of Obj1, Obj2, and Obj3 are the same with these in (25), (27), and (30). The coupling parts, such as $\frac{\partial\left|V_{\mathrm{poc}}\right|}{\partial P_{\mathrm{wt}}}$ in (28) and $\frac{\partial\left|V_{\mathrm{wt}}\right|}{\partial P_{\mathrm{wt}}}$ in (29), are neglected.

The sampling period $t_{\mathrm{s}}$ is set as $1 \mathrm{~s}$, which is further divided into 5 small steps: $n_{\mathrm{s}}=5$. The prediction horizon $t_{\mathrm{p}}$ is set as $5 \mathrm{~s}$. The simulation time is $240 \mathrm{~s}$.

\section{A. Case Scenario 1: Low power production}

In Case 1, the simulation period is $0 \sim 120 \mathrm{~s}$. The power production of the wind farm $P_{\mathrm{wf}}$ for both controllers (SEP and $\mathrm{COM}$ ) and the available wind power $P_{\mathrm{wf}}^{\mathrm{avi}}$ are shown in Fig. 7. It can be observed that $P_{\mathrm{wf}}$ of both controllers are almost identical, which strictly track the specified ramp rate limit and increases from $65 \mathrm{MW}$ to $87 \mathrm{MW}$ within the range of $P_{\mathrm{wf}}^{\mathrm{avi}}$.

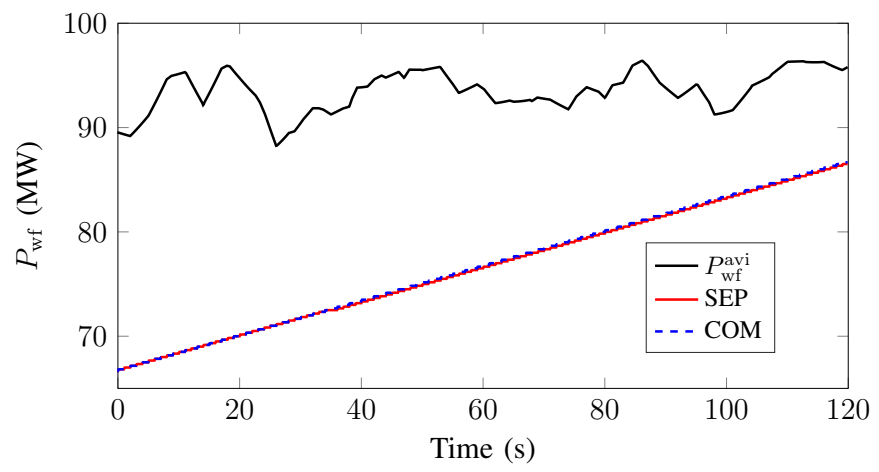

Fig. 7. Power production of the wind farm for Case 1.
Due to the low $P_{\mathrm{wf}}$, from the whole wind farm point of view, the Var capacities of WTGs are large, which implies more Var reserves and voltage support capability. The voltages at two representative buses are used to illustrate the voltage condition of the wind farm, including $V_{\mathrm{poc}}$ and $V_{\mathrm{wt} \_} 15$, which is located at WT15, the furthest bus along the feeder (see Fig. 1). As shown in Fig. 8, all the voltage deviations are within their thresholds and the WFC operates in the normal mode.

(a)

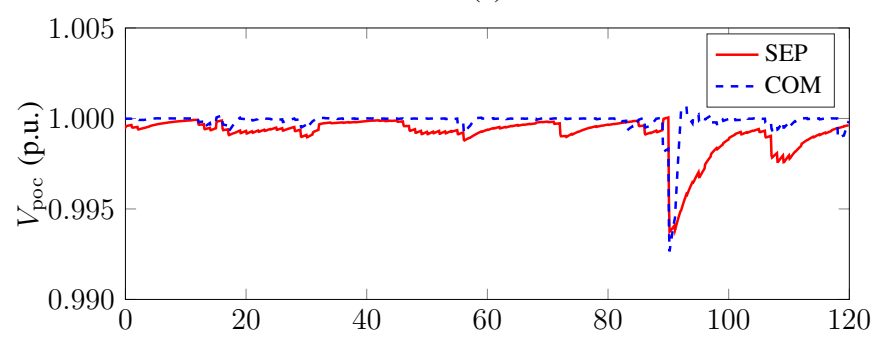

(b)

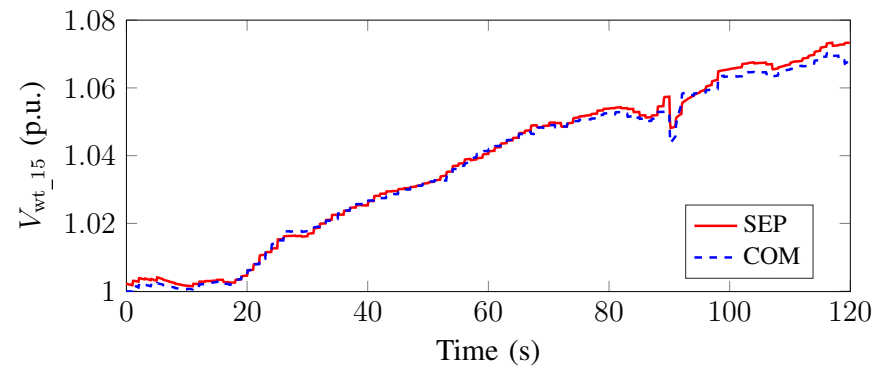

Fig. 8. Voltages at POC and WT15 for Case 1.

The Damage Equivalent Load (DEL) based on Miner's rule is used to evaluate the fatigue load minimization. By means of the toolbox MCrunch [26], the DELs of the whole wind farm for both controllers are calculated and listed in Table II, which are almost the same. It implies the same control performances of the load minimization for both controllers.

TABLE II

DEL OF WIND FARM

\begin{tabular}{c|c|c}
\hline \hline & SEP & COM \\
\hline \hline DEL in MNm & 43.08 & 43.10 \\
\hline
\end{tabular}

Since $W_{\text {poc }}>W_{\mathrm{wt}}, V_{\mathrm{poc}}$ of both controllers are regulated quite close to its reference value $V_{\text {poc }}^{\text {ref }}=1$ p.u., as shown in Fig. 8(a). Comparably, the voltage deviation with COM is smaller. Even for a sudden change due to the power fluctuation, the recovery of $V_{\text {poc }}$ to $V_{\text {poc }}^{\text {ref }}$ is faster. Due to the power increase, the voltage $V_{\mathrm{wt} \_} 15$ increases. The increase rate of COM is smaller. Therefore, considering the impact of active power on the voltage, COM shows better voltage controllability.

The Var output of the SVG $Q_{\mathrm{s}}$ for both controllers are shown in Fig. 9. In this case, $Q_{\mathrm{s}}^{\text {mid }}=0$. As the slow Var reserve of WTGs is enough for the voltage support, only small $Q_{\mathrm{s}}$ is detected for both controllers. $Q_{\mathrm{s}}$ of COM is smaller, which means more fast Var capacity is reserved. 


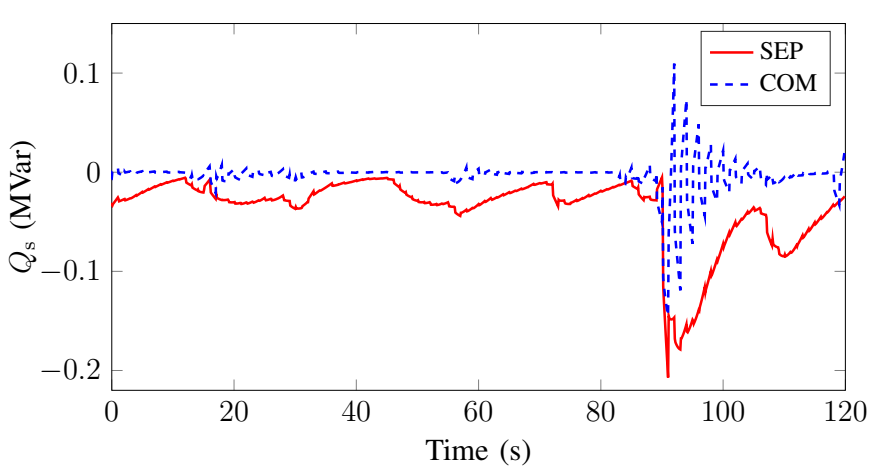

Fig. 9. Var output of the SVG $Q_{\mathrm{s}}$.

\section{B. Case Scenario 2: High power production}

In Case 2, the simulation period is $120 \sim 240 \mathrm{~s}$. The available wind power $P_{\mathrm{wf}}^{\mathrm{avi}}$ and $P_{\mathrm{wf}}$ for both controllers (SEP and COM) are shown in Fig. 10. It can be observed that $P_{\mathrm{wf}}$ of both controllers are almost identical, which ranges from $87 \mathrm{MW}$ to $100 \mathrm{MW}$, close to the capacity limit.

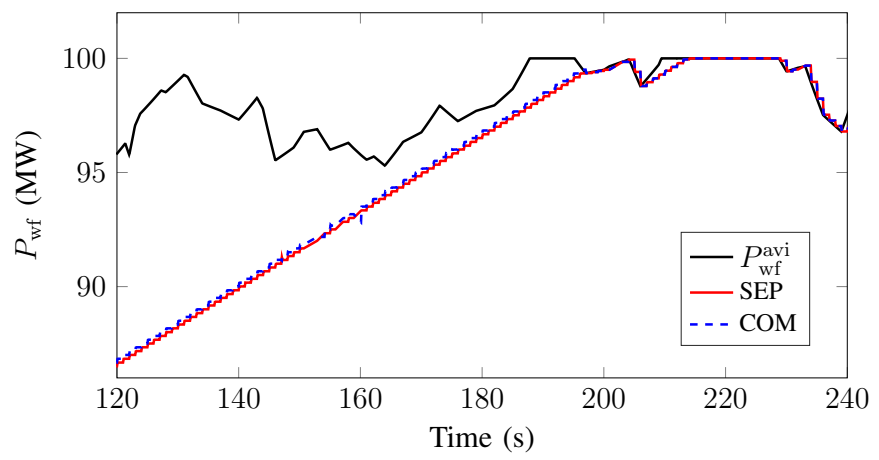

Fig. 10. Power production of the wind farm for Case 2.

Since $P_{\mathrm{wf}}$ is high, the active power of several WTGs is high, which may significantly affect their Var capacities. By defining,

$Q_{\mathrm{wt}}^{\mathrm{sum}} \triangleq \sum_{i=1}^{N_{\mathrm{wt}}} Q_{\mathrm{wt}}, Q_{\mathrm{wt}}^{\mathrm{s} \_\mathrm{min}} \triangleq \sum_{i=1}^{N_{\mathrm{wt}}} Q_{\mathrm{wt}}^{\mathrm{min}}, Q_{\mathrm{wt}}^{\mathrm{s} \_\mathrm{max}} \triangleq \sum_{i=1}^{N_{\mathrm{wt}}} Q_{\mathrm{wt}}^{\max }$,

where $Q_{\mathrm{wt}}^{\mathrm{sum}}$ denotes the total Var production of WTGs, $Q_{\mathrm{wt}}^{\mathrm{s} \_m i n}$ and $Q_{\mathrm{wt}}^{\mathrm{s} \text { min }}$ are the lower and upper limits of the total Var capacity of WTGs, respectively. Their simulation results are shown in Fig. 11. It can be observed that the Var capacity range of COM is larger than that of SEP, especially during the periods $t_{1}=201.3 \mathrm{~s} \sim 207.6 \mathrm{~s}$ and $t_{2}=232.2 \mathrm{~s} \sim 236 \mathrm{~s}$. For $\mathrm{SEP}$, due to the decoupled active and reactive power control, $Q_{\mathrm{wt}}^{\min }$ and $Q_{\mathrm{wt}}^{\min }$ can't be predicted. There are sudden decreases of the total Var capacity in $t_{1}$ and $t_{2}$. Accordingly, the voltage support capability are reduced in these periods. For COM, $Q_{\mathrm{wt}}^{\mathrm{min}}$ and $Q_{\mathrm{wt}}^{\min }$ can be predicted based on the predictions of $P_{\mathrm{wt}}$ and $V_{\mathrm{wt}}$. The possible Var shortage is considered in the MPC. Therefore, the total Var capacity is kept stable for the whole period.

The voltage results are shown in Fig. 12. For SEP, $V_{\text {poc }}$ is often beyond its operation limits [0.98 p.u., 1.02 p.u.] (Fig.

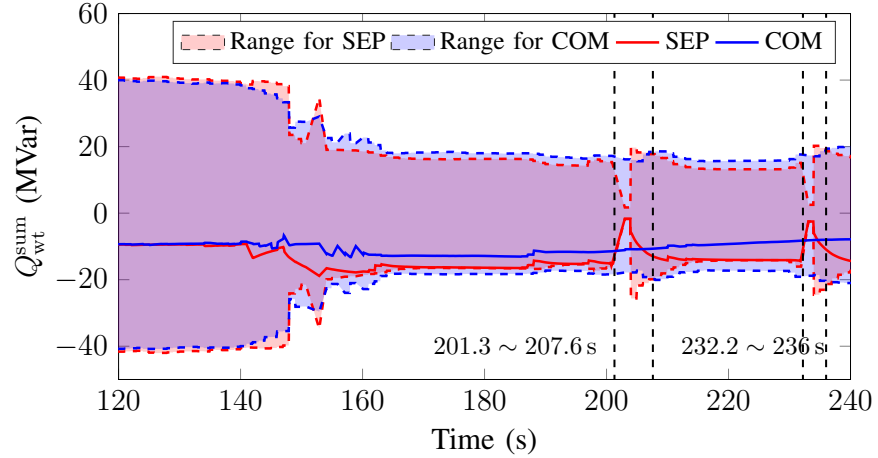

Fig. 11. Var capacity of WTGs.

(a)

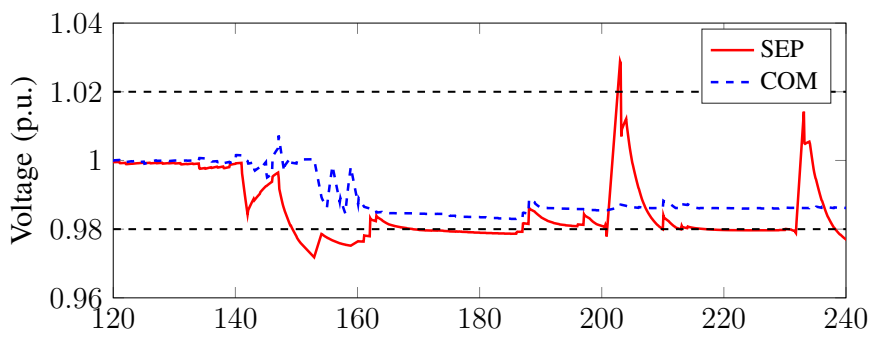

(b)

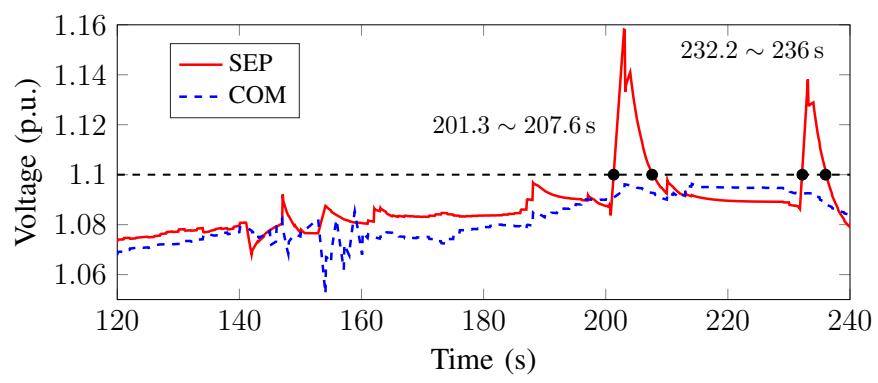

Fig. 12. Voltages at POC and WT15 for Case 2.

12(a)). Due to the shortage of the Var reserve, $V_{\text {wt_15 }}$ breaks the protection limit (1.1 p.u.) during $t_{1}$ and $t_{2}$, which will trigger the protection devices in real operation and may cause a cascading failure (Fig. 12(b)). For COM, the voltage deviations are smaller. $V_{\text {poc }}$ is always regulated within its limit. $V_{\mathrm{wt} \_} 15$ is never beyond the protection limit.

\section{Case Scenario 3: Different $X / R$ ratios}

Due to the low $X / R$ ratio, the active power change has an impact on the voltage variation. In this study, $X / R=0.65$. The significance of the impact is largely dependent on the $X / R$ ratio. In this case, the control performances between SEP and COM for different $X / R$ ratios are compared. The standard deviation of the voltage at the POC, $\sigma\left(\Delta V_{\text {poc }}\right)$, is used as a representative index to quantify the control performance. The results are listed in Table III. It can be observed that with the decrease of $X / R$ ratio, the impact becomes more significant. The $\sigma\left(\Delta V_{\text {poc }}\right)$ of SEP increases from 0.0025 p.u. to 0.0117 p.u.. Compared with SEP, COM can significantly reduce the $\sigma\left(\Delta V_{\text {poc }}\right)$. The reduction ranges from $28.0 \%$ to $38.6 \%$. 
TABLE III

COMPARISON OF $\sigma\left(\Delta V_{\text {poc }}\right)$

\begin{tabular}{c|c|c|c}
\hline \hline$\sigma\left(\Delta V_{\text {poc }}\right)$ & SEP & COM & Reduction \\
\hline \hline$X / R=1.50$ & 0.0025 p.u. & 0.0018 p.u. & $-28.0 \%$ \\
\hline$X / R=1.00$ & 0.0101 p.u. & 0.0068 p.u. & $-32.7 \%$ \\
\hline$X / R=0.65$ & 0.0114 p.u. & 0.0070 p.u. & $-38.6 \%$ \\
\hline$X / R=0.50$ & 0.0117 p.u. & 0.0084 p.u. & $-28.2 \%$ \\
\hline
\end{tabular}

\section{CONCLUSION}

In this paper, the MPC based combined WFC is developed to optimally coordinate the active and reactive power regulation devices with different time constants for better voltage control. Two control modes are designed according to the voltage conditions. For the normal mode, without disturbing the active power control performances, including tracking the power reference of the wind farm and minimizing the fatigue loads, the active and reactive power is optimally coordinated to minimize the voltage deviation of the buses, especially the voltage of the POC, and maximize the fast Var capacity to handle the potential disturbance. For the emergency mode, the regulation of the violated voltages back to their limits is the only control objective. The potential of the active and reactive power for the voltage support is fully utilized. The case studies show the proposed combined scheme can efficiently coordinate the power regulation devices and significantly improve the voltage controllability and stability of the wind farm. The practical concerns for the application of a real wind farm system, including the communication delay and on-line model identification, will be studied in the future work.

\section{APPENDIX}

The derivation of the state space model of SVC/SVG for the proposed WFC, (8), can be divided into three steps.

Step 1: Calculation of $Q_{\mathrm{s}}^{\text {ref }}$.

Substitute (6) and (7) into (5), (5) can be transformed into,

$$
\begin{aligned}
Q_{\mathrm{s}}^{\text {ref }}= & Q_{\mathrm{s}}^{0}+K_{\mathrm{p} \_\mathrm{s}_{\mathrm{s}}}\left(V_{\mathrm{s}}^{\mathrm{ref}}-V_{\mathrm{s}}^{0}-\frac{\partial\left|V_{\mathrm{s}}\right|}{\partial Q_{\mathrm{s}}} \Delta Q_{\mathrm{s}}-\frac{\partial\left|V_{\mathrm{s}}\right|}{\partial P_{\mathrm{wt}}} \Delta P_{\mathrm{wt}}\right. \\
& \left.-\frac{\partial\left|V_{\mathrm{s}}\right|}{\partial Q_{\mathrm{wt}}} \Delta Q_{\mathrm{wt}}\right)+K_{\mathrm{i} \_\mathrm{s}} V_{\text {int }} .
\end{aligned}
$$

By defining

$$
\Delta V_{\mathrm{s}}^{0} \triangleq V_{\mathrm{s}}^{0}-\frac{\partial\left|V_{\mathrm{s}}\right|}{\partial Q_{\mathrm{s}}} Q_{\mathrm{s}}^{0}-\frac{\partial\left|V_{\mathrm{s}}\right|}{\partial P_{\mathrm{wt}}} P_{\mathrm{wt}}^{0}-\frac{\partial\left|V_{\mathrm{s}}\right|}{\partial Q_{\mathrm{wt}}} Q_{\mathrm{wt}}^{0},
$$

Equation (35) can be transformed into,

$$
\begin{aligned}
Q_{\mathrm{s}}^{\mathrm{ref}}= & Q_{\mathrm{s}}^{0}+K_{\mathrm{p} \_\mathrm{s}}\left(V_{\mathrm{s}}^{\mathrm{ref}}-\frac{\partial\left|V_{\mathrm{s}}\right|}{\partial Q_{\mathrm{s}}} Q_{\mathrm{s}}-\frac{\partial\left|V_{\mathrm{s}}\right|}{\partial P_{\mathrm{wt}}} P_{\mathrm{wt}}-\frac{\partial\left|V_{\mathrm{s}}\right|}{\partial Q_{\mathrm{wt}}} Q_{\mathrm{wt}}\right) \\
& -K_{\mathrm{p} \_\mathrm{s}} \Delta V_{\mathrm{s}}^{0}+K_{\mathrm{i}_{\mathrm{s}} \mathrm{s}} V_{\mathrm{int}} .
\end{aligned}
$$

Step 2: Derivation of the differential equation of $Q_{\mathrm{s}}$.

Equation (4) can be transformed into the following differential equation,

$$
\dot{Q}_{\mathrm{s}}=-\frac{1}{\tau_{\mathrm{s}}} Q_{\mathrm{s}}+\frac{1}{\tau_{\mathrm{s}}} Q_{\mathrm{s}}^{\mathrm{ref}}
$$

Substitute (36) into (37),

$$
\begin{aligned}
\dot{Q}_{\mathrm{s}}= & -\frac{1}{\tau_{\mathrm{s}}}\left(1+K_{\mathrm{p} \_\mathrm{s}} \frac{\partial\left|V_{\mathrm{s}}\right|}{\partial Q_{\mathrm{s}}}\right) Q_{\mathrm{s}}+\frac{K_{\mathrm{i} \_\mathrm{s}}}{\tau_{\mathrm{s}}} V_{\mathrm{int}}+\frac{K_{\mathrm{p} \_\mathrm{s}}}{\tau_{\mathrm{s}}} V_{\mathrm{s}}^{\mathrm{ref}} \\
& -\frac{K_{\mathrm{p} \_\mathrm{s}}}{\tau_{\mathrm{s}}} \frac{\partial\left|V_{\mathrm{s}}\right|}{\partial P_{\mathrm{wt}}} P_{\mathrm{wt}}-\frac{K_{\mathrm{p} \_\mathrm{s}}}{\tau_{\mathrm{s}}} \frac{\partial\left|V_{\mathrm{s}}\right|}{\partial Q_{\mathrm{wt}}} Q_{\mathrm{wt}}+\frac{Q_{\mathrm{s}}^{0}}{\tau_{\mathrm{s}}}-\frac{K_{\mathrm{p} \_\mathrm{s}}}{\tau_{\mathrm{s}}} \Delta V_{\mathrm{s}}^{0} .
\end{aligned}
$$

Step 3: Derivation of the differential equation of $V_{\text {int }}$.

Equation (7) can be transformed into the following differential equation,

$$
\dot{V}_{\text {int }}=\left(V_{\mathrm{s}}^{\text {ref }}-V_{\mathrm{s}}\right) .
$$

Substitute (6) into (39),

$$
\begin{aligned}
\dot{V}_{\text {int }} & =\left(V_{\mathrm{s}}^{\text {ref }}-V_{\mathrm{s}}\right) \\
& =V_{\mathrm{s}}^{\text {ref }}-V_{\mathrm{s}}^{0}-\frac{\partial\left|V_{\mathrm{s}}\right|}{\partial Q_{\mathrm{s}}} \Delta Q_{\mathrm{s}}-\frac{\partial\left|V_{\mathrm{s}}\right|}{\partial P_{\mathrm{wt}}} \Delta P_{\mathrm{wt}}-\frac{\partial\left|V_{\mathrm{s}}\right|}{\partial Q_{\mathrm{wt}}} \Delta Q_{\mathrm{wt}} \\
& =V_{\mathrm{s}}^{\text {ref }}-\frac{\partial\left|V_{\mathrm{s}}\right|}{\partial Q_{\mathrm{s}}} Q_{\mathrm{s}}-\frac{\partial\left|V_{\mathrm{s}}\right|}{\partial P_{\mathrm{wt}}} P_{\mathrm{wt}}-\frac{\partial\left|V_{\mathrm{s}}\right|}{\partial Q_{\mathrm{wt}}} Q_{\mathrm{wt}}-\Delta V_{\mathrm{s}}^{0}
\end{aligned}
$$

Based on (38) and (40), the state space model of SVC/SVG can be derived,

$\left[\begin{array}{c}\dot{Q}_{\mathrm{s}} \\ \dot{V}_{\mathrm{int}}\end{array}\right]=\boldsymbol{A}_{\mathrm{s}}\left[\begin{array}{c}Q_{\mathrm{s}} \\ V_{\mathrm{int}}\end{array}\right]+\boldsymbol{B}_{\mathrm{s}} V_{\mathrm{s}}^{\mathrm{ref}}+\boldsymbol{E}_{\mathrm{s}} P_{\mathrm{wt}}+\boldsymbol{F}_{\mathrm{s}} Q_{\mathrm{wt}}+\boldsymbol{G}_{\mathrm{s}}$ with

$$
\begin{aligned}
& \boldsymbol{A}_{\mathbf{s}}=\left[\begin{array}{cc}
-\frac{1}{\tau_{\mathrm{s}}}\left(1+K_{\mathrm{p} \_\mathrm{s}} \frac{\partial\left|V_{\mathrm{s}}\right|}{\partial Q_{\mathrm{s}}}\right) & \frac{K_{\mathrm{i} \_\mathrm{s}}}{\tau_{\mathrm{s}}} \\
-\frac{\partial\left|V_{\mathrm{s}}\right|}{\partial Q_{\mathrm{s}}} & 0
\end{array}\right], \boldsymbol{B}_{\mathbf{s}}=\left[\begin{array}{c}
\frac{K_{\mathrm{p} \_\mathrm{s}}}{\tau_{\mathrm{s}}} \\
1
\end{array}\right], \\
& \boldsymbol{E}_{\mathbf{s}}=\left[\begin{array}{c}
-\frac{K_{\mathrm{p} \_\mathrm{s}}}{\tau_{\mathrm{s}}} \frac{\partial\left|V_{\mathrm{s}}\right|}{\partial P_{\mathrm{wt}}} \\
-\frac{\partial\left|V_{\mathrm{s}}\right|}{\partial P_{\mathrm{wt}}}
\end{array}\right], \boldsymbol{F}_{\mathrm{s}}=\left[\begin{array}{c}
-\frac{K_{\mathrm{p}_{\mathrm{s}} \mathrm{s}}}{\tau_{\mathrm{s}}} \frac{\partial\left|V_{\mathrm{s}}\right|}{\partial Q_{\mathrm{wt}}} \\
-\frac{\partial\left|V_{\mathrm{s}}\right|}{\partial Q_{\mathrm{wt}}}
\end{array}\right], \\
& \boldsymbol{G}_{\mathbf{s}}=\left[\begin{array}{c}
-\frac{K_{\mathrm{p}_{\mathrm{s}} \mathrm{s}} \Delta V_{\mathrm{s}}^{0}}{\tau_{\mathrm{s}}}+\frac{Q_{\mathrm{s}}^{0}}{\tau_{\mathrm{s}}} \\
-\Delta V_{\mathrm{s}}^{0}
\end{array}\right] .
\end{aligned}
$$

\section{REFERENCES}

[1] Global Wind Energy Council (GWEC), Global wind report: annual market update 2015, GWEC, Brussels, 2016.

[2] M. Tsili and S. Papathanassiou, "A review of grid code technical requirements for wind farms," IET Renew. Power Gen., vol. 3, no. 3, pp. 308-332, 2009.

[3] Q. Wu, Z. Xu, and J. Østergaard, "Grid integration issues for large scale Wind Power Plants (WPPs)," in Proc. of IEEE PES General Meeting, Minneapolis, 2010

[4] P. E. Sørensen, A. D. Hansen, K. Thomsen, T. Buhl, P. E. Morthorst et al., Operation and control of large wind turbines and wind farms-final report, Tech. Rep., Ris $\varnothing-\mathrm{R}-1532$, Ris $\emptyset$ National Laboratory, 2005.

[5] P. E. Sørensen, A. D. Hansen, F. Iov, F. Blaabjerg, and M. H. Donovan, Wind farm models and control strategies, Tech. Rep., Ris $\varnothing-\mathrm{R}-1464$, Ris $\emptyset$ National Laboratory, 2005.

[6] T. Knudsen, T. Bak, and M. Svenstrup, "Survey of wind farm controlpower and fatigue optimization," Wind Energy, vol. 18, no. 8, pp. $1333-1351,2015$

[7] V. Spudić, M. Jelavić, and M. Baotić, "Wind turbine power references in coordinated control of wind farms," Automatika-Journal for Control, Measurement, Electronics, Computing and Communications, vol. 52, no. 2, 2011.

[8] B. Biegel, D. Madjidian, V. Spudic, A. Rantzer, and J. Stoustrup, "Distributed low-complexity controller for wind power plant in derated operation," in IEEE International Conference on Control Applications (CCA), 2013, pp. 146-151. 
[9] H. Zhao, Q. Wu, Q. Guo, H. Sun, and Y. Xue, "Distributed model predictive control of a wind farm for optimal active power control-Part II: Implementation with clustering-based piece-wise affine wind turbine model," IEEE Trans. Sustain. Energy, vol. 6, no. 3, pp. 840-849, 2015.

[10] W. Qiao, R. G. Harley, and G. K. Venayagamoorthy, "Coordinated reactive power control of a large wind farm and a STATCOM using heuristic dynamic programming," IEEE Trans. Energy Convers., vol. 24, no. 2, pp. 493-503, 2009.

[11] Q. Guo, H. Sun, B. Wang, B. Zhang, W. Wu, and L. Tang, "Hierarchical automatic voltage control for integration of large-scale wind power: Design and implementation," Electric Power Systems Research, vol. 120, pp. 234-241, 2015.

[12] H. Zhao, Q. Wu, Q. Guo, H. Sun, S. Huang, and Y. Xue, "Coordinated voltage control of a wind farm based on model predictive control," IEEE Trans. Sustain. Energy, vol. 7, no. 4, pp. 1440-1451, 2016.

[13] H. Amaris, M. Alonso, and C. A. Ortega, Reactive Power Management of Power Networks with Wind Generation, Springer Science \& Business Media, 2012.

[14] E. F. Camacho and C. B. Alba, Model predictive control, Springer Science \& Business Media, 2013.

[15] J. D. Grunnet, M. Soltani, T. Knudsen, M. Kragelund, and T. Bak, "Aeolus toolbox for dynamic wind farm model, simulation and control," in Proc. of the 2010 European Wind Energy Conference, 2010.

[16] J. M. Jonkman, S. Butterfield, W. Musial, and G. Scott, Definition of a $5-M W$ reference wind turbine for offshore system development, National Renewable Energy Laboratory, Colorado, 2009.

[17] J. Soens, J. Driesen, and R. Belmans, "Equivalent transfer function for a variable speed wind turbine in power system dynamic simulations," International Journal of Distributed Energy Resources, vol. 1, no. 2, pp. 111-133, 2005

[18] E. V. Larsen and A. S. Achilles, "System and method for voltage control of wind generators," US Patent No. 9,318,988, 19 Apr. 2016.

[19] F. Z. Peng and J.-S. Lai, "Dynamic performance and control of a static var generator using cascade multilevel inverters," in Proc. of IEEE Industry Applications Conference, pp. 1009-1015, 1996.

[20] D. Jovcic and K. Ahmed, High Voltage Direct Current Transmission: Converters, Systems and DC Grids, John Wiley \& Sons, 2015.

[21] J. M. Maciejowski, Predictive control: with constraints, Pearson education, 2002.

[22] D. K. Khatod, V. Pant, and J. Sharma, "A novel approach for sensitivity calculations in the radial distribution system," IEEE Trans. Power Del., vol. 21, no. 4, pp. 2048-2057, 2006.

[23] K. Christakou, J. LeBoudec, M. Paolone, and D.-C. Tomozei, "Efficient computation of sensitivity coefficients of node voltages and line currents in unbalanced radial electrical distribution networks," IEEE Trans. Smart Grid, vol. 4, no. 2, pp. 741-750, 2013.

[24] Y. Wang and S. Boyd, "Fast model predictive control using online optimization," IEEE Trans. Control Syst. Technol., vol. 18, no. 2, pp. 267-278, 2010.

[25] B. Fox, Wind power integration: connection and system operational aspects, IET, 2007.

[26] M. L. Buhl, MCrunch user's guide for version 1.00, National Renewable Energy Laboratory, 2008.

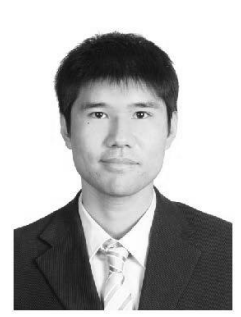

Haoran Zhao (S'12-M'15) received the B.E. degree in electrical engineering and automation from Shandong University, Jinan, China, in 2005, the M.E. degree in electrical engineering and automation from the Technical University of Berlin, Berlin, Germany, in 2009, and the Ph.D. degree in electrical engineering from the Technical University of Denmark, Kgs. Lyngby, Denmark, in 2015.

$\mathrm{He}$ is a Postdoc with the Center for Electric Technology, Technical University of Denmark. He worked as Electrical Engineer with State Grid Corporation of China (SGCC), Beijing, China, in 2005. From August 2010 to September 2011, he worked as Application Developer with DIgSILENT $\mathrm{GmbH}$, Gomaringen, Germany. His research interests include modeling and integration study of wind power, control of energy storage system, and voltage stability analysis.

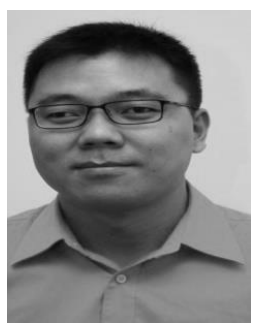

Qiuwei Wu (M'08-SM'15) obtained the B. Eng. and M. Eng. in Power System and Its Automation from Nanjing University of Science and Technology, Nanjing, China, in 2000 and 2003, respectively. $\mathrm{He}$ obtained the PhD degree in Power System Engineering from Nanyang Technological University, Singapore, in 2009.

He was a senior R\&D engineer with VESTAS Technology R\&D Singapore Pte Ltd from Mar. 2008 to Oct. 2009. He has been working at Department of Electrical Engineering, Technical University of Denmark (DTU) since Nov. 2009 (PostDoc Nov. 2009-Oct. 2010, Assistant Professor Nov. 2010-Aug. 2013, Associate Professor since Sept. 2013). He was a visiting scholar at Department of Industrial Engineering \& Operations Research (IEOR), University of California, Berkeley, from Feb. 2012 to May 2012 funded by Danish Agency for Science, Technology and Innovation (DASTI), Denmark. He has been a visiting professor named by Y. Xue, an Academician of Chinese Academy of Engineering, at Shandong University, China, since Nov. 2015.

His research interests are smart grids, wind power, electric vehicle, active distribution networks, electricity market, and smart energy systems. He is an Editor of IEEE Transactions on Smart Grid and IEEE Power Engineering Letters. He is also an Associate Editor of International Journal of Electrical Power and Energy Systems.

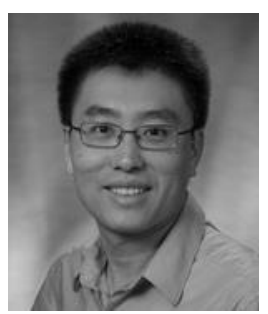

Jianhui Wang (M'07-SM'12) received the Ph.D degree in electrical engineering from Illinois Institute of Technology, Chicago, IL, USA, in 2007.

Presently, he is the Section Lead for Advanced Power Grid Modeling at the Energy Systems Division at Argonne National Laboratory, Argonne, IL, USA. He is also an affiliate professor at Auburn University and an adjunct professor at the University of Notre Dame.

Dr. Wang is the secretary of the IEEE Power \& Energy Society (PES) Power System Operations Committee. Before being promoted and elected to this position, he was the chair of the IEEE PES Power System Operation Methods Subcommittee for six years. He is the Editor-in-Chief of IEEE TRANSACTIONS ON SMART GRID, an editor of the IEEE TRANSACTIONS ON POWER SYSTEMS, an associate editor of the Journal of Energy Engineering, an editor of the IEEE PES LETTERS, and an associate editor of Applied Energy. He is an IEEE PES Distinguished Lecturer.

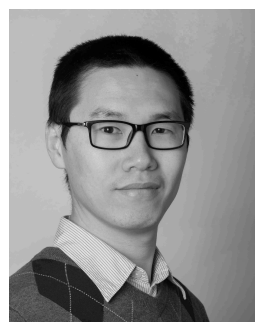

Zhaoxi Liu Zhaoxi Liu received the B.S. and M.S. degrees in electrical engineering from Tsinghua University, Beijing, China, and the Ph.D. degree from Technical University of Denmark, Denmark, in 2006, 2008, and 2016, respectively.

$\mathrm{He}$ is currently a PostDoc in Center for Electric power and Energy (CEE), Department of Electrical Engineering, Technical University of Denmark. His research interests include power system operations and integration of distributed energy resources in power systems. 


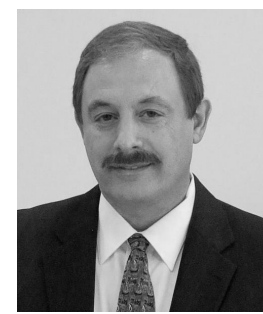

Mohammad Shahidehpour (F'01) is the Bodine Chair Professor with the Department of Electrical and Computer Engineering, the Director of the Robert W. Galvin Center for Electricity Innovation, and an Associate Director of WISER with the Illinois Institute of Technology, Chicago, IL, USA.

He was a recipient of the IEEE PES Outstanding Power Engineering Educator Award, the IEEE PES Outstanding Engineer Award, and the Chicago Chapter. He is the Holder of Nourbakhshian Endowed Chair Professorship, University of Kashan, Iran, and Otto Monsted Professorship, Technical University of Denmark. He is a Research Professor with King Abdulaziz University, Saudi Arabia, the Sharif University of Technology, Iran, as well as several universities in China, including Tsinghua University, Xian Jiaotong University, Nanjing University, North China Electric Power University, and Hunan University. He is an IEEE PES Distinguished Lecturer, and served as the VP of Publications for the IEEE Power and Energy Society, the Editor-in-Chief of the IEEE TRANSACTIONS ON POWER SYSTEMS, and the Founding Editor-in-Chief of the IEEE TRANSACTIONS ON SMART GRID.

Dr. Shahidehpour is a member of the U.S. National Academy of Engineering.

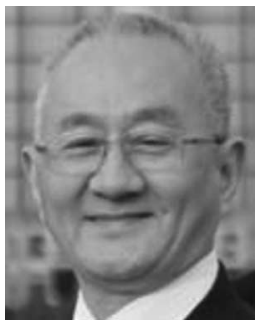

Yusheng Xue (M'88) received the M.Sc. degree in electrical engineering from EPRI, China, in 1981, and the Ph.D. degree in electrical engineering from the University of Liege, Liege, Belgium, in 1987. He was elected as an Academician of the Chinese Academy of Engineering in 1995.

$\mathrm{He}$ is now the Honorary President of State Grid Electric Power Research Institute (SGEPRI or NARI), China. He holds the positions of Adjunct Professor in many universities in China and is a Conjoint Professor with the University of Newcastle, Callaghan, NSW, Australia. He is also an Honorary Professor with the University of Queensland, Brisbane, Qld., Australia. He has been a member of the PSCC Council, and the Editorin- Chief of Automation of Electric Power System since 1999, and a Member of Editorial Board of IET Generation, Transmission, and Distribution, and Chairman of Technical Committee of Chinese National Committee of CIGRE since 2005. 